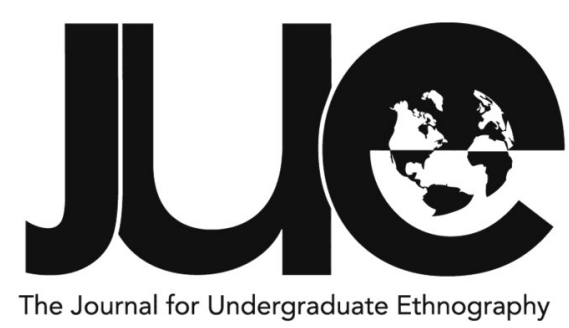

\title{
Stories of Transnationalism: nǐ kàn wǒ, wǒ kàn nǐ (你看我, 我看你)
}

\section{Yuxian Seow}

University of Western Australia, yuxianseow@gmail.com

\section{ABSTRACT}

Transnationalism has been explored in scholarship within the scope of migration and globalisation. Often, related literature and theories conceptualise and deconstruct transnationalism within the framework of methodological nationalism. However, new scholarship suggests that the outdatedness of this framework results in its failure to adapt to, capture, and better understand the complexity and intersectionality of transnationalism in the contemporary context. Drawing on an autoethnographic account of my transnational relationship with my grandmother, this paper delves into the individual everyday perspective of transnationalism and the impacts it has had on facilitating the emergence of transmigrant identities, creating a sense of belonging, and transforming care networks that span the globe. It is a collection of short stories that offers a level of insight, meaning, understanding, being there, and co-presence (Baldassar, Nedelcu, Merla, and Wilding 2016) that exemplifies the contemporary transnational relationship and the ways in which it has been shaped by the digital space, rapid globalisation, and narratives of migration. By researching transnationalism from a qualitative and ethnographic methodology, this paper explores the embeddedness of a "here and there" dynamic (Duong 2015, 233) that has come to reflect a profoundly felt sense of interconnectivity between loved ones. Finally, this study prompts existing researchers and scholarship to critically engage with and adapt their ways of researching transnationalism in the global context.

Keywords: transnationalism; transnational identities; transnational narratives; ethnography; transnational families 


\section{星期天 (Sunday)}

Our conversation takes place at the intersection of Mandarin, English, and Singlish. I tone down my Australian accent on the phone so that she can pick up the English words that I am unsure of how to translate. It is Sunday and our scheduled phone call is via WhatsApp. She answers the phone on the third ring, and I greet her, "hello Āmā (阿嫲)." “Xiăomāo (小猫),"

There I am a young child all over again, laughing as I descend the stairs of home, the old colonial bungalow, Āmā (阿嫲) is smiling and encouraging me to take the next step. This image of her is suspended in time, [this is the photo I carry with me,] this is the woman who raised me in my first year of life; this is the woman who healed my spirits when I fled home to Singapore as a heartbroken eighteen-year-old.

She is home to me now in the questions that open up tangents to family drama, inside jokes, how I'm doing in school, Grandpa's declining health, and her laughing at my attempts to fit Chinese words into an English sentence. It is as if she is sitting across from me, on the balcony of our new home, a high rise Singaporean apartment, in the cool morning breeze. There we are eating watermelon seeds and always laughing.
Instead, I am in my orange-painted room in Perth, alone. There are no watermelon seeds, no cool breeze on a balcony. She is 3912 kilometres away and it is another 76 days before I will see her again.

Our phone calls begin to bridge the distance, we share funny messages, photos, updates about our daily lives, we FaceTime, and because of this, we maintain a close relationship despite the overwhelming physical distance. I can feel her smiling through the phone; she is so proud that she is able to navigate her smartphone as a way of navigating this distance.

It makes missing us less difficult. 


\section{Focus of the Research}

These are snapshot encounters that capture a day of the week in which a phone call took place between me and my grandmother. They explore topics of conversations, experiences, memories, and the context of our transnational relationship. They serve as a collection of short stories that offers a level of insight, meaning, understanding, and being there across distances that exemplifies the contemporary transnational relationship and how it has been shaped by the digital space, rapid globalisation, and our own narratives of migration. Stories that illuminate the transformative and symbolic aspects of phone calls between individuals who span across distances are often missed in more structuralist approaches to researching transnationalism (Bal 1990). These stories are a style of ethnography that draws heavily from narratology, both as an attempt to do justice to the social subject of the transmigrant and to understand better and beyond more traditional approaches of studying transnationalism. The implications of applying a narratology methodology to ethnographic inquiry can be seen in this paper; that is, these snapshot encounters between me and my grandmother illuminate the increasingly transnational nature of our everyday lives.

The approach of anthropology as storytelling is not a new one. Anthropology as a "discipline engaged in explaining, understanding, and interpreting cultural worlds" (McGranahan 2015) uses storytelling as a methodology to make sense of new cultural worlds. This way of organising writing and grounding theoretical approaches in ethnographic inquiry captures a more holistic element of subject and ethnographer that begins to constitute a greater understanding of anthropology. Pioneers of anthropology as storytelling include Clifford Geertz (1973) and his method of thick description, which prompted a new way of ethnographic inquiry that draws heavily on the recording aspect of ethnography. In writing thickly, scientific observations and the description of things as they are lay the groundwork for anthropological interpretation, and thus aid researchers in interpreting the meaning of things and making sense of a cultural world. Alongside this search for the symbolic and meaning in interactions, the narratology approach also further illustrates an understanding grasped in a being there. The concept of being there echoes the richness of similar terms in transnational literature like "copresence" (Baldassar, Nedelcu, Merla, and Wilding 2016). In utilising the methodology of narratology, these snapshot encounters of Grandma and I's transnational relationship on WhatsApp readily allows us to be there with each other and experience "co-presence".

Narrative is thick and expressive; it fashions experiences so that they can be understood by others and, in doing so, also explains and allows for an interpretation that informs anthropologists and researchers in the field of transnationalism. These narratives transform to become more than stories of childhood, home, language, and family; they are thick descriptors that grow to signify the greater symbolic interaction of the phone call within a transnational field and examine the increasingly transnational nature of our lives.

The research is presented in a way that focuses on the individual and the self, informed by other styles of autoethnography similar to Dana Walrath (2011), Rebecca Raab (2018), Anne Harris (2016), and Jonathan Wyatt (2012), all of whose personal experiences and their introspective, inductive, reflective, and creative methodologies have been able to deepen their understanding of their subjects of inquiry. Their creative methodologies, which produced rich qualitative data, provide a real lived-in experience within their research and research subjects that I aimed to embody within my own research.

These transnational narratives are intertwined with theoretical sections that explore aspects of Grandma's and my shared transnational experience through our digital interactions in the polymedia environment, the phenomenon of global ageing, the emergence of transmigrant identities, the role of language, and ways of belonging within the transnational context. By interweaving these theories and theoretical frameworks within an overarching transnational narrative, I hope to reimagine and reframe the ways in which transnationalism as a concept is understood; moreover, I aim to move beyond the notion of a nation-state 
society that often contains transnationalism. Furthermore, this research helps to transform the methodologies that are employed to understand transnational relationships by exploring the role of narratives in providing a nuanced richness to ethnographic research and the creative capacities of ethnography in the field of transnationalism.

Inspired by Miller's (2009) style of ethnography on the individual, which examines the relationship between studies of society and the individual, my research focuses on the individual subject and self. Often in ethnographic research, scholarship follows the direction of societal behaviours and cultures rather than focusing on the personal. Miller argues that there is a holistic nuance that arises from research focused on the individual, as the individual is the microcosm that reflects the macrocosm of society: "the individual as exemplifying the precise position he or she holds in society and reproducing at this scale the same sense of order and expectation we recognize as that of the society as a whole" (Miller 2009, 13). My own research follows this theoretical approach by examining how an individual's microcosmic transnational interactions are transformed to reproduce a transnational interaction that exists at a macrocosmic, global level. This reproduces a cultural code (Miller 2009) that exemplifies contemporary transnational interactions within the complexities and intersectionality of the transnational context. Miller argues that choosing the individual as a subject choice is often overlooked when an individual actor within society can provide a unique cultural experience that reflects and exemplifies a greater cultural nuance within that society.

In the context of my research, this paper discusses theories of transnationalism, Wilding and Baldassar's (2018) global ageing, Duany's (2011) transnational activities and transnationalism as practice, and the transformative force of the symbolic phone call, which takes place in a polymedia environment. These factors all facilitate the emergence of the transmigrant identity and one's navigation of human connection and belonging amidst the acceleration of interconnectivity in the globalised world.

\section{Methods}

During October of 2018, I conducted participant observation and a semi-formal interview via phone calls with my grandmother on the social media app WhatsApp. Each phone call was between fifteen to sixty minutes long and was conducted in my own home. The initial phone call was a semi-formal interview that followed a list of questions about the usage, interaction, and engagement with WhatsApp. All other conversations were informal and inductive, and they included a range of conversation topics: university, academic life, family drama, our holiday in December, my student exchange in 2019, Grandpa, my brother, Grandma's technology classes, yoga, catching up with friends, my love life, things that happened in my childhood, and my upcoming trip to Singapore. Notes were taken during the phone call followed by self-reflective journaling after the experience. Participant observation consisted predominantly of listening and engaging with the conversation; as a result, interesting stories, experiences, and personal histories emerged from the overall experience. The decision to focus the scope of my research on such a deeply personal aspect of my own life has allowed for a level of interaction, observation, and living in the experience that would otherwise be inaccessible to the public.

The initial interest at the beginning of this research project focused on the ways that two different families engaged and interacted, using WhatsApp as a means of communicating and maintaining transnational relationships. This research idea also fit within the scope of theories of transnationalism, transnational identities, transnational families, globalisation, and the digital space. However, after the first two weeks of research, with a majority of interviews completed, I came to realise that there was far too much data and research to surmise, analyse, and present in a wordconstrained essay format. Thus the decision to transition to an individual research subject was made. The hope is for more creative methodological research on transnational families and transnational identities to be expanded in future research and publications on transnationalism by demonstrating the creative capacities of narratology in ethnographic research. 
Stories have been a way for people to form human connections in a myriad of contexts, across cultures and across time. In writing about the transnational family relationship (Baldassar, Kilkey, Merla, and Wilding 2014) I share with my grandmother, it seemed fitting to tell a story: her story, my own-our story. A narrative of migration, family, human connection, and belonging. So, in the wisdom of McGranahan's (2015) words, I begin with the story "that can't be left out" (McGranahan 2015), starting with the earliest memory of Grandma and the first thing that comes to mind when I think of home. These short stories have now come to reflect our kind of transnational relationship_an entwined family history of migration and our navigation of belonging and connectivity-so that in each phone call, we are actively meaning-making and loving each other across temporalities and spatialities.

\section{Why Transnationalism?}

Transnationalism is not a new concept. Much like globalisation, it has "assumed a greater scale, intensity, diffusion, and velocity at the turn of the twenty-first century" (Duany 2011, 28). As such, transnationalism has become one of the most "promising potentials for social research for the twenty-first century" (Duany $2011,29)$. It is an important area of scholarship that critically examines and engages with the interactions of individual actors and their participation in both their home societies and host societies such that they are able to develop multiple, overlapping identities, "lead bifocal lives, express loyalties to more than one nation state, and practice hybrid cultures" (Duany 2011, 24). While there are many dimensions to transnationalism, including emotional, physical, economic, and political, my research examines the concept within the framework of transnational care, family, and memory. This section of the paper will discuss the significance of studying and researching transnationalism. It will first outline more traditional approaches to transnational research by discussing the paradigm of methodological nationalism that has historically dominated migration studies. Building on this, it will be examining more contemporary theoretical approaches to migration and transnational studies that frame this research project.

Transnationalism has been explored in a variety of ways in research, including politically within discourses of modern nation-states and the integration and assimilation of migrant populations into the dominant culture of their host societies. It has also been examined economically with the increased flow of trade, capital, and labour. Transnationalism has been considered, now more critically, within cultural and social dimensions, identity construction, belonging, and transnationalism as practice. Historically, the concept of transnationalism has been explored because it formed a counter to dominant models of assimilation in migrant discourses. These assimilationist models have been approached through methodological nationalism, which is a theoretical framework that dominates migration studies and transnational scholarship. Methodological nationalism has become increasingly outdated in examining the contemporary realities of transnationalism as it "confines the study of social processes to the political and geographical boundaries of a particular nationstate" (Levitt and Glick-Schiller 2004, 1007). Examples of this can be seen in classical migration studies and topics of cultural homogenisation through the assimilationist model.

Balogun (2011) uses the theoretical framework of the segmented assimilation paradigm to understand the processes of identity formation among second-generation Nigerians in the United States. Segmented assimilation "proposes congruence between economic, structural and identificational forms of incorporation in which identity is formed in part through the second generation's mobility prospects" (Balogun 2011, 459). The paper, based on twenty-five semi-structured interviews, delves into the lives of secondgeneration Nigerian immigrants in the Bay area of San Francisco. The author's analysis shows the heavy influence of methodological nationalism. Assimilation is posited in opposition to the maintenance of transnational ties, and the intersection of transnationalism and assimilation is only seen briefly as a possibility in the process of identity formation. The focus of segmented assimilation examines 
the incorporation of migrants and the subsequent second generation into host societies and the impacts of the assimilation on identity formations. This incorporative approach is similarly seen in Asher's (2008) article on hyphenated Asian-American youth identities. Once again, the postcolonial perspective toward hybrid identities contributes to the traditional assimilationist frameworks that fall within methodological nationalism. The hybridity argument limits itself to this framework as it examines the experiences of second-generation migrants as a product of their parents' narratives of migration. In moving away from this framework of methodological nationalism and toward a more transnational perspective, second-generation migrants can be seen to be negotiating their ways of being and belonging and the challenges that come within the narrative of migration. Their identity formations, whether hyphenated, hybrid, or not, are not only informed by their own experiences, in this case in American society, but also by the experiences of their parents and the generations before them.

Furthermore, transnationalism is not strictly a first-generation phenomenon. The new paradigm of transnationalism moves away from power structures like hegemony, assimilation, and oppression that have long dominated the debate. Instead, it examines more deeply and broadly the human and lived-in experiences of belonging and interconnectedness between home and host, family and self that begins to encompass the complexity of "multi-layered, multi-sited transnational social fields" (Levitt and Glick-Schiller 2004, 1003) that illuminate the realities of transnationalism in the contemporary context. In moving toward this new paradigm, new methodologies that deepen our knowledge and understanding of multilayered and multi-sited approaches are needed. The nature of our lives is becoming increasingly transnational, especially heightened by the use of digital technology. Ethnographic inquiry and the relevant theoretical frameworks must evolve alongside these rapid changes and complex processes at play.

Levitt and Glick-Schiller (2004) propose studying social processes beyond the theoretical framework of methodological nationalism, which "rejects the long-held notion that society and the nation-state are one and the same" (1003). In moving beyond the framework of methodological nationalism, studies of social processes can be deepened and broadened; more specifically, migrants and the impacts of their mobilities can be seen as "embedded in multi-layered, multi-sited transnational social fields, encompassing those who move and those who stay behind" (1003). Since Levitt and Glick-Schiller's (2004) paper, new transnational and migration research has emerged that pushes for this new paradigm of framing transnational studies. Early and late 2000s migration researchers who specialise in transnationalism and transnational families have also begun to further examine how transnationalism has been a transformative force that impacts transnational relationships, social interactions, caregiving, and transnational identities (see Baldassar 2016; Baldassar and Merla 2013; Merla 2015; Merla and Baldassar 2011; Nedelcu 2013).

Increasingly, contemporary research has looked into the role that information and communication technologies (ICTs) have played in shaping co-presence across distances (Baldassar, Nedelcu, Merla, and Wilding 2016) and how these communicative technologies have facilitated the being there and embedded "here and there" dynamic (Duong 2015, 233) that is so deeply felt in transnational relationships. Terms like being there, "copresence" (Baldassar, Nedelcu, Merla, and Wilding 2016) and "here and there" (Duong 2015,233 ) are able to capture the nuanced richness of transnational relationships, transnational care, and belonging that reflect a greater interconnectivity in the overall transnational framework. Research into transnationalism has also begun to help uncover global inequalities and rising power asymmetries by making them more visible. This can be examined from the perspective of transnationalism as resistance, which is described as "counter hegemony and embodying subaltern resistance to existing structures of domination" (Duany 2011, 31), whether it be political domination or cultural assimilation policies.

Researchers and scholars, although with competing claims about how transnationalism should be studied and examined, have come to 
a consensus about the importance of transnationalism as a concept, an idea, a process, and a practice that has been incredibly influential in a myriad of research topics. Ethnography that examines transnationalism and its presence in the lives of individuals and society "now has the task of determining the nature of locality, as lived experience in a globalised, deterritorialized world"' (Appadurai 1991 as cited in Glick Schiller, Basch, and Blanc $1995,49)$. How does our understanding of the locality of transnationalism that Appadurai conceptualises shape and influence our understanding of new and emerging interactions, engagements, and connections that increasingly occur in the digital space? This research aims to contribute to existing theories and literature on transnationalism and to rethink and reframe transnationalism within the intersection of global ageing, interconnectivity, migration, and belonging. Transnationalism is paramount in the twentyfirst century; it is happening now, across the globe, as the "quiet revolution" (Wilding and Baldassar 2018, 227) that is taking place and transforming the ways in which we connect to one another. The emergence of the transmigrant identity is accelerating the sense of interconnectivity that has been a by-product of rapid globalisation. Symbolic interactions between individuals, families, and communities are now able to take place beyond the physical spaces that scholarship has grown accustomed to. These relations have shifted into the digital space; communication and the meanings that are gained from it are now occurring on social media apps, on phone calls, and through text messaging.

\section{Transnational and Transmigrant Identities in a Social Field}

The emergence of transnational identities amidst studies of migration and globalisation challenges long-held assertions and understandings about the modern nation-state and society, including the ways in which transnationalism has been studied within the container framework of the nation-state and the metaphor of borders. This section of the paper follows the previously discussed contemporary theoretical approaches to studying and researching transnationalism. It explores the new paradigm proposed by Levitt and Glick Schiller (2004) and Bourdieu's social field as a new transnational lens.

Emerging identities-such as Asian-American or Chinese-born Australian-increasingly challenge the rigidity of nation-state societies, as they are often perceived as threats to social cohesion, unity of the nation, and how these migrant groups are incorporated and assimilated into nation-state societies. Furthermore, the emergence of transnational identities also challenges the presupposition that incorporating migrants into host societies can only occur in binary and contradiction to the maintenance of transnational connections. Hyphenated and transnational identities have come to symbolise hybrid individuals who have ties to both their home and host society as well as loyalties and allegiances to more than one nation-state. Transnational identities in this sense are often studied from the perspective of globalisation and diaspora; their hybridity is explored as resistance to the dominant culture, with the retainment of ties to home societies seen as a way of resisting assimilation processes into the host society (Bhabha 1994).

In applying a transnational lens, migration can be studied outside of the framework of methodological nationalism. Rather than viewing new migrants or transnational identities as either assimilating, resistant, or hybrid, the transnational lens allows for the simultaneity of an incorporative attitude toward one's host society and the maintenance of ties with their home society. A migrant with strong ties to home and host society is no longer seen as one that has trouble with assimilation or letting go of their ties to home; rather, they can now be viewed as a transnational individual. Amidst accelerated globalisation in the twentyfirst century, the methodological nationalism model of understanding transnational identities fails to grasp the complex interconnectedness of these identities with a person's home and loved ones. It retains and strongly asserts the binary view that the incorporation of individuals into a host society is a direct contradiction to the maintenance of transnational connections to home. The nation-state framework provides only a limited understanding of what transnational and migration scholarship can understand and capture of social ties and wider 
society. How can we as anthropologists better understand what constitutes society and what its boundaries are, if there are any? And what are the implications to our ways of researching and studying transnationalism as a global phenomenon?

The increased movement of people from home to host society, both online and offline, has made the local more global. Transnational identities are emerging from spaces where the local and global intersect in a myriad of ways online and offline that involve complex social processes of being and belonging in all aspects of social life. Transnational actors are increasingly able to access and participate in these spaces, such that even individual actors without a narrative of migration can now be considered transnational individuals, simply because their daily lives see them interacting in the transnational sense.

In their paper, Levitt and Glick Schiller (2004) propose a "new paradigm" (1003) that considers the possibility of studying transnationalism and emergent transnational identities beyond the methodological nationalism framework. The paper critically examines the contemporary transnational lens from the theoretical framework of Bourdieu's social field and looks at how transnational actors are able to pivot between the intersections of their social lives. Levitt and Glick Schiller propose the concept of Bourdieu's social field as a framework by which transnationalism and emergent transnational identities can be better understood as "a single social field created by a network of networks" (1009). In this sense, the authors describe the social field

as a set of multiple interlocking networks of social relationships through which ideas, practices and resources are unequally exchanged, organised, and transformed... social fields are multidimensional, encompassing structured interactions of differing forms, depth and breadth that are differentiated in social theory by the terms of organization, institution, and social movements. (1009)

Levitt and Glick Schiller argue that the framework of methodological nationalism has become rather outdated and fails to "capture, adequately or automatically, the complex interconnectedness of contemporary reality" (Levitt and Glick Schiller 2004, 1006). Instead, transnationalism, which at its core examines a "profound [sense of] interconnectivity" (Duong 2015, 232), can no longer be "confined by nation-state boundaries" (Levitt and Glick Schiller 2004, 1007).

Instead, this "new paradigm" (Levitt and Glick Schiller 2004, 1003) of social fields engages with transnational interactions between individuals, institutions, religions, genders, politics, geography, and language in the global sense. The social field, as theorised by Bourdieu, allows for research on migration to be examined within the scope of ways of being and ways of belonging (Levitt and Glick Schiller 2004) all within one social field. Thus, connections between individuals who are migrants themselves and between those who are left behind can be examined through the concept of social networks. Transnational communication typically occurs via social media or by networks like nostalgia, memory, and imagination. These networks can be critically engaged with either as ways of being, ways of belonging, or the simultaneity of both. By moving forward from the framework of methodological nationalism, nation-state society is understood as having significance to the social lives of transnational identities but is set aside in order to examine the space in which interconnectedness occurs as a global phenomenon. The global social field becomes the macrocosm of the nation-state society, with the interactions of transnational individuals serving as the stimulation of social networks that link actors all over the world. These networks span across and beyond the borders and boundaries of nation-states. This ties in with Miller's style of ethnography, which comes to exemplify and signify the macrocosmic social field when examining the individual interactions of social actors in transnational networks. Within this framework of Bourdieu's social field, coupled with Miller's style of ethnography on the individual, we can begin to see the emergence of transnational and transmigrant identities at the global level.

These symbolic interactions between individuals-a phone call, a text, or a plane ride-contribute to ways of being and 
belonging to family, loved ones, and ideas of home that Levitt and Glick Schiller (2004) argue are how individuals participate in transnational ways of being, which are "the actual social relations and practices that individuals engage in" (1010). These types of interactions are also essential to transnational individuals' ways of belonging, which recognize that transnational activities and the acknowledgement and expression of belonging are "practices that signal or enact an identity which demonstrates a conscious connection to a particular group" (1010). Belonging is both an action, in the transnational activity, and the selfawareness required to acknowledge and express that sense of belonging in the transnational framework. By moving forward from methodological nationalism, the global macrocosm can now be understood as Bourdieu's social field; therefore, everyone who is practicing ways of being and ways of belonging in the transnational sense can thus be considered transnational individuals.

These networks of networks that facilitate the emergence of transnational identities can begin to be understood, studied, examined, and grasped beyond the spatialities of borders that have long dominated transnational discourse. Now, the "profound [sense of] interconnectivity" (Duong 2015, 232) that Duong writes of can be grasped as both immensely complex and paramount to further research on migration, transnationalism, and globalisation, especially within the socio-cultural sense that examines how belonging occurs. This new paradigm lens of ethnographic inquiry proposes that individual interactions with other social actors across and beyond nation-state borders have come to exemplify how ways of being are experienced within the transnational framework; the transnational activities of texting, calling, and sending mixed media through apps like WhatsApp are an accessible form of transnational being. Due to the social participation of transnational activities, the recognition, acknowledgement, and expression of them thus exemplify the wider social phenomenon of transnational belonging. What distinguishes transnational identities from transmigrant identities is the narrative of migration. Unlike transmigrant identities, transnational individuals are not distinguished by a personal narrative of migration; they may simply be transnational because of their participation in transnational ways of being. These transnational actors may interact within the intersection of the global and local in their online and offline lives in ways that allow them to be and belong transnationally even without migration. Their everyday social lives see them participating in the transnational sense and leading transnational lives, even by simply FaceTiming friends who are abroad. Within my research, my grandmother's and my ways of being become inextricably entwined with our ways of belonging. By framing my own research within Levitt and Glick Schiller's (2004) new paradigm of the global transnational network, Bourdieu's social field, and Miller's style of ethnography, the interactions between the two of us can be examined more critically within the wider social implications of shifting theoretical paradigms in migration and transnational studies. The narratology approach to qualitative ethnographic inquiry illuminates the increasingly transnational nature of our lives. We are both transnational social actors in our online interactions; because of our participation in transnational ways of being, our everyday interactions with each other include sending messages and photos that bridge the distance and span across nation-state boundaries. Yet, we are also transmigrant individuals because, through our interactions, we have grown to acknowledge and express that sense of belonging to one another, to our places of being, and to our own narratives of migration.

Through this transformational process of participation in the online, individual social actors who use social media apps like WhatsApp are actively participating in ways of transnational being. In further recognizing, acknowledging, and expressing these ways of transnational being, individual actors begin to belong transnationally. Thus, they create, maintain, and retain ties to multiple spatialities, home and host, which exist beyond notions of nation-state society and must now be engaged with within the wider scope of a macrocosmic global field. 


\section{星期三 (Wednesday)}

The family portraits are hung up on the walls of the new apartment. Picture frames that hold my mother, uncles, and grandparents in another time. There are photos of them as children, as teenagers, and later in their graduation gowns. These are followed by portraits that include my aunt and father and my uncle's fiancée at the time (who is now his wife). The last twenty years of photos include a new grandchild every five years. First my cousin and I in 1998 as babies, then my brother in 2000 and cousins in 2001, 2002, 2003, two in 2005, and the last one in 2010.

The family photo in December is a highly anticipated family reunion event that occurs every five years. It is a tradition that has been carried out for the last fifty years, and this year marks the fiftieth anniversary of my grandparents. We traverse through time zones and over distances on planes and cars to meet in one house to take the family portrait. 阿嫲 (Āmā) fears that this year will be the last family portrait with everyone in it. It is something that she repeats to me in every conversation.
For us, it is a way of remembering, capturing, and freezing in time a memory. The portraits are a portal through time, when the children were still children, and it was a race to be the tallest in the family. It captures the memory of the frantic energy of sixteen people trying to be still together for a moment in time.

The photo frames have evolved from small ones on the walls to larger dominating pictures, and now the family portraits are on our computer desktop screens and our phones. We carry them with us wherever we go. To say this is my family, this is where I come from. 


\section{星期四 (Thursday)}

My grandparents grew up on the same street in Old Colonial Singapore during the late 1950s. They were friends as teenagers and were married in their early twenties despite disapproval from my Āmā's (阿嫲) family. There is a Singaporean documentary made in 1995 about my GōngGong (公公) ${ }^{3}$ that depicts the unconventional path that has forged the life my grandparents share today. My GōngGong (公公) was thirty-eight years old when he attended Nanyang Technological University. ${ }^{4}$ Āmā (阿嫲) was the breadwinner of the family of five, while he was the first in the family to receive a tertiary education. The whole arrangement was unheard of; this was especially noted on my GōngGong's (公公) first day of university when he received a standing ovation from his peers as he entered the room. They had mistaken him as their professor.

Nowadays my grandparents still share that same bond, unwavering in the face of societal expectations and attitudes. In our conversation, Āmā (阿嫲) speaks endearingly of GōngGong's (公公) struggle to write an email in Chinese to a relative in China. It is as if they are teenagers again, Āmā (阿嫲) crouched over a small writing desk in Little India tutoring my GōngGong (公公) in English; they are back in 1956 on Upper Dickinson Road. GōngGong (公公) doesn't know how to write in pinyin, which is the English Romanisation system used to sound out words into Chinese characters on many word processors and smartphones.
This isn't because of dementia or any other neurological conditions inhibiting his ability to process words, but rather that his everyday life requires him to communicate in English digitally, such that even GōngGong (公公) is losing touch with the Chinese language, relying on my Āmā (阿嫲) more and more to fill in the blanks of his drafted email. She is the link between him and the Chinese language. Even now they are supporting each other as they navigate the digital world together. 


\section{Findings}

\section{Symbolic Interactionism in the}

\section{Transnational Context}

Historically, transnational interactions and relationships have been supported by sending remittances and letters with interactions limited by geographical distances, air transportation, political stability, and economic security. The growing digital space via the conduit of social media apps like WhatsApp is transforming the ways in which individuals, families, and communities can engage, interact, and connect. Transnationalism facilitated by information and communication technologies (ICTs) is a relatively new phenomenon that has emerged in the last two decades or so. Its emergence presents interesting debates on our anthropological understandings of social interactions and how they have transformed through our online interactions. Herbert Blumer (1969) outlines three premises of symbolic interactionism that are useful for understanding this transformation of social interactions. These are, firstly, "that human beings act toward things on the basis of the meanings that the things have for them" (2). Secondly, "the meaning of such things is derived from, or arises out of, the social interaction that one has with one's fellows" (2). And thirdly, "that these meanings are handled in, and modified through, an interpretive process" (2).

From the theoretical framework of symbolic interactionism, social and online interactions are studied and interpreted as meaningful and meaning making. This theoretical framework has been applied to the study of online and offline personas and Goffman's theory of performance of self (Hogan 2010; Bullingham and Vasconcelos 2013). Hogan, Bullingham and Vasconcelos, and others have explored in their research how social actors in their online engagements and symbolic interactions have constructed an online self which differs from their offline personas. This greatly influences individual social actors and their selfidentification processes, as well as having huge potentials for the field of symbolic interactionism and its applicability to the online world and online interactions. These online interactions and individuals' engagement with online worlds have widened the scope of symbolic interactionism in ethnographic inquiry and have furthermore transformed the landscape in which the sociocultural processes of transnationalism can be studied.

The phone call in this sense becomes more than just the symbolic interaction between two or more people; it becomes what Duany (2011) calls a transnational activity and has overtaken previous practices of transnational activities. Participation in transnational activities like WhatsApp, which is digital, makes transnational practices and activities more expansive and accessible, transforming the landscape in which symbolic interactionism and understandings about existing transnational practices, identities, and relationships form and evolve. As phone calls are occurring in a digital space, this form of symbolic interaction is taking place at "[the] intersection of local and global" (Gajjala 2006, 179), such that individuals are increasingly able to partake in a multiplicity of cultures as a means of "selective acculturation" (Duany 2011, 25), thus rejecting the assimilationist framework that has long dominated migration discourses. It has led to the emergence of new evolving, transmigrant identities that maintain ties to ethnic, cultural, and home societies whilst simultaneously forging new cultural identities in their host societies. In my own interactions with Grandma, I am drawing from and remaining connections with my home society, Singapore, whilst simultaneously partaking in Australian society, which has led to the eventual self-identification of my own transmigrant, Asian-Australian identity. Through our phone calls, texts, and photos, we are remaining connected in our relationship through language, personal history, memories, storytelling, and participating in the everyday of each other's lives via our WhatsApp interactions. 
Without the time to try and translate the last two words, I used a Chinese-English dictionary app to translate the whole sentence. Skimming over the dictionary meanings, my eyes settled on travel lightly and so I replied regarding my suitcase. It wasn't until later that day when we talked on the phone that I asked about the suitcase in question. Āmā (阿嫲) had no idea why I was telling her about my suitcase.

I had mistranslated the message, fumbled the English alphabet into a Chinese sentence. Mistaking lǘxíng (旅行) for xíngli (行 李). Āmā (阿嫲) is laughing as she explains that lǘxíng (旅行) is a holiday, not a suitcase. The travel agent had called to confirm our trip to China.

In an echo of my mistake, Āmā (阿嫲) recounts the time she copy and pasted an entire research essay of mine into Google translate because she was struggling to understand some of the academic jargon. She said that Google made such a mess of my essay that none of it made sense. She resorted to translating the individual words so that the meaning of my essay would not be lost in translation.

We are always meeting at this intersection of language, an overlapping mixture of Chinese, Singlish, and English, trying to understand each other. Without the physical capability to communicate with our hands, bodies, and facial expressions, we are always having to explain more in depth, rather than having the words to say it for us. To say it is like this, or no, this is what I was trying to say-we are grasping to catch the meanings that are vulnerable to being lost in translation.

It is like when she says nǐ kàn wǒ, wǒ kàn nǐ (你看我, 我看你); it means more than just the literal translation of you see me, / see you. It is as Geertz says: "a speck of behaviour, a fleck of culture, and voilà - a gesture!" (Geertz 1975, 312). Grandma is saying, "I see all of you and you see all of me." It is our kind of symbolic interaction.

\section{育贤:你的旅行ok! 승 4:39 pm}

\section{Okay! I have a red suitcase and a suitable carry on bag or backpack




\section{A Polymedia Environment}

Within the contemporary context, a heightened engagement within Madianou and Miller's (2012) polymedia environment has taken precedence in research concerning migration, mobility, identities, globalisation, and intersectionality. The polymedia environment, a term utilised and coined by Madianou and Miller (2012), describes "an emerging environment of communicative opportunities" (170) that are set out by three preconditions: access and availability, affordability, and media literacy. The term polymedia environment is useful in examining human interactions in the new paradigm of transnationalism. Within the contemporary context, the uses of technological means of communication are accelerated and, in framing these interactions within the polymedia environment, the methodological implications toward studying transnationalism are epic. At its core, "the environment of polymedia becomes inextricably linked to the ways in which interpersonal relationships are enacted and experienced" (Madianou and Miller 2012, 170-171), especially within the transnational framework. Increased interactions between loved ones through media as a means to overcome distance and space challenges previous conceptions of remittance and connection.

Furthermore, the preconditions for a polymedia environment are becoming increasingly accessible. In conjunction with the understanding of transnational activities, the interactions of migrants with loved ones via various media technologies can be seen to be taking place in a polymedia environment, instantaneously. As a result, my grandmother and I are able to adapt our relationship to the diversity and complexity of navigating transnational care networks amidst ageing, migration, digital media, and other factors that impact our relationship: language, culture, history, and storytelling. Thus, in our phone calls, photos, and text messages, we are caring for one another, no matter the time zone or distance-Grandma's ability to navigate digital media allows her to connect to and care for all of us, no matter where we are in the world. In this, we are able to sustain the "complex multilayered relationships of exchange and interaction over time [and distance]" (Wilding and Baldassar 2018, 230).

Research into and on transnationalism seeks to capture the lived-in experiences of individuals and families and the processes by which transnational practices are taking place as a means to navigate one's place in the world and their identity. In doing so, we can better understand the phenomenon of transnationalism and its wider social implications toward existing concepts and understandings of human connection and interaction.

Transnationalism becomes increasingly available to more and more people in the polymedia environment (Madianou and Miller 2012). As a result, transnationalism has begun to diminish the power of the nation-state to adapt to and keep up with the ever-evolving and increasing presence of overlapping migrant identities that transcend traditional nation-state borders. New sets of social relations develop and converge within a polymedia space. With the preconditions of access and availability, affordability, and media literacy (Madianou and Miller 2012), migrants and their left-behind loved ones are able to access polymedia technologies as a means of navigating their transnational relationships. This shift between the social and technological transforms the ways in which transmigrants are increasingly able to access technology as a means to connect with loved ones and practice transnationalism in their everyday lives. An increasing "need for transnational communication between migrants and their left -behind families is particularly acute" (170) with the rapid growth of polymedia networks. Through social networking apps like WhatsApp, the transnational space has expanded beyond the home, organisations, institutions, and nation-states and is now "experienced globally" (170). The transnational space is now able to take place in the online sphere, making it accessible and instantaneous. As such, transmigrants are able to combine their experiences of "origin and settlement [societies] to create a new kind of self-awareness" (Duany $2011,25)$ within the everyday lived-in experience of transnationalism. Thus, transnationalism takes place beyond theoretical 
notions of the nation-state and its physical bounded localities.

As seen in this research, transnationalism within the contemporary context can be explored in a myriad of ways. It can frame research on global ageing and the ways in which everyday transnational practices facilitate the emergence of transmigrant identities. In this sense, transnationalism in the polymedia environment embodies both the local and trans -local notions of culture, identity, and aid in the negotiation of "two competing claims, thereby redrawing the lines between home and host societies" (Duany 2011, 33). Applying the transnational lens to this research highlights the emergence of the transmigrant identity because of its accessibility and ability to exist in the everyday experiences of migrants. As a migrant herself, Grandma simultaneously forges her transmigrant identities in her interactions with her children and grandchildren who have also migrated elsewhere. By interacting in the polymedia environment and using a range of accessible and available multimedia, Grandma practices transnationalism every day, such that her children and grandchildren are also beginning to forge their own transmigrant identities in their replies, phone calls, and interactions with her. Migration is now intertwined with the family narrative of connection, belonging, origin, and history within the transnational context.

\section{Global Ageing in the Transnational \\ Context}

Amidst the phenomenon of global ageing, scholarship has begun to engage with and delve into the intersectionality of ageing, migration, digital media, and the transformative processes that are occurring within this intersection. Wilding and Baldassar (2018) explore the emergence of new care networks and the ways in which new media are transforming, shaping, and providing "unprecedented opportunities to bring distant places and people together in new ways" (226), particularly the elderly and their connections with younger family members. This emerging and transformative care network has huge impacts on ageing and migrant identities; migration in this sense has become a paramount signifier in the familial narrative by transforming the ways in which kin members are providing care for one another. With these new care networks, families and loved ones are challenging the commonly held assumption that care requires proximity, thus revolutionising conceptualisations of care in the transnational context.

This transformative process of caregiving and global ageing is characterised by Wilding and Baldassar (2018) as a "quiet revolution" (227) that exists at the intersection of care, migration, globalisation, and digital media, contributing to an expansive growth in the nature of care networks within the scope of global ageing. Traditionally, within discourses on migration and global ageing, the elderly are often identified as a vulnerable group. There are those who are migrants themselves (ageing migrants), those who migrate at a later stage in life (migrant elderly), and those who are "characterised by their own lack of migration" (228), the left-behind elderly. However, Wilding and Baldassar argue that the emergence of new care networks via new media transforms the need for proximity in maintaining formal and informal methods of care, such that "proximity is no longer necessary for the exchange of informal support within families" (229). Digital networks and new media are increasingly used to facilitate "copresence" (230), which enables a here-there form of symbolic interaction in which family members and loved ones are able to stay connected and supported even across distances and time.

Symbolic interactionism is heavily evident in my research as the emergence of transnational care networks transform how my grandmother and $I$ are able to communicate, interact, and connect through various forms of new media via WhatsApp. By using features like FaceTime, text, and sending photos, videos, and voice memos, we are participating in the "quiet revolution" (Wilding and Baldassar 2018, 227) and are actively practicing transnationalism. Thus, the communication between my grandmother and I challenge the presupposition that proximity is a necessity; we are simultaneously navigating the distance of our relationship and the emergence of our own left-behind and transmigrant identities. Our interaction in the "polymedia 
environment" (Madianou and Miller 2012) mobilises the transnational relationship that we already have.

\section{Transnational Activities}

When the lens of transnationalism is applied to this research, what are normally understood to be everyday activities are transformed to be transnational activities that function within the bigger picture of transnationalism. The everyday phone calls and texts with loved ones "across multiple spatialities and temporalities" (Duong 2015, 233) have now transformed within the contemporary context to be transnational activities. Within this scope, contemporary activities in a highly digitised world with the use of mixed media messaging and calling are now considered alongside other transnational activities like trade, migration, sending remittances, and letter writing, thus transforming the scope in which transnationalism can be considered an activity and as a practice. It has made transnationalism even more expansive and accessible. With the click of a button, the sending of a photo, or an instant message, transmigrants all over the world who connect with their loved ones across spatialities and temporalities are practicing transnationalism in their everyday lives. How individual actors participate in these activities have had and will continue to have huge impacts on both the ways in which human interactions can be understood and the creation of a sense of "co-presence" (Wilding and Baldassar 2018, 230). This co-presence, a "here-there" (Duong 2015, 233), is a means to selectively acculturate and maintain a sense of elasticity in one's migrant identities and one's navigation of belonging.

Contemporary researchers have also begun to examine this aspect of transnationalismbelonging and transnational relationshipsparticularly by focusing on transnational families. Baldassar, Kilkey, Merla, and Wilding (2014) consider new concepts of care networks that aim to capture these rapidly evolving aspects of transnationalism. Information and communication technologies like WhatsApp contribute to shaping ways of belonging and to strengthening relationships across distances. However, relationships that are being transformed by communication technologies vary. In the same way that people interact differently in various physical settings, these differences also occur in the online sphere. What is undeniable, however, are the effects that these information and communication technologies (ICTs) have on individuals and how they manage and navigate "multiple belongings, [and] learn to live with a multiple sense of self" (Baldassar, Kilkey, Merla, and Wilding 2014, 137).

These new and emerging forms of transnationalism as practice and as activities are revolutionising the ways in which transnationalism can be studied. Now, individual actors, families, and communities are also able to participate in a form of contemporary everyday transnationalism. They are able to create their own "profound [sense of] interconnectivity" (Duong 2015, 232) and a here-there dynamic (Duong 2015) of copresence (Wilding and Baldassar 2018, 230) as their means to navigate the distance and their own narrative of migration and belonging. This is illustrated by the ways that my grandmother and I navigate our own transnational relationship through our phone calls and texts. 


\section{星期天 (Sunday)}

I am staring at the blinking cursor on the blank page of Microsoft Word. It has been opened for forty-five minutes now. I am wondering where to begin the story of the strong, beautiful, and wonderful woman that is my grandma and of what I have learnt in this research project. It is a story that is filled with so much history, meaning, context, experience, and memory.

In the wisdom of McGranahan's words, I begin with the story "that can't be left out," starting with the earliest memory of Grandma and the first thing that comes to mind when I think of home. This expands to stories of things that are yet to happen, of family, my grandparents, and meaning that is lost in translation at the intersection of language.

This project has intensified longings for home and to be in the company of my grandparents. During the course of this research project, I have changed my flight home such that I'm leaving five weeks earlier than anticipated. There is a countdown app on my phone and it says that it is 6 days, 20 hours and 31 minutes before my plane takes off from the tarmac of Perth International Airport. 


\section{Reframing Transnationalism}

In the same way that two billion other WhatsApp users (Bucher 2020) communicate with their loved ones and share their love and care transnationally, my own engagement and interactions with a loved one has informed and allowed for a more nuanced understanding of transnational relationships, the emergence of transnational identities, global care networks, and ways of being and belonging. By living within my research and engaging with my grandmother in such a deeply personal dimension of my life, the entirety of this ethnographic experience has provided a more holistic perspective on the symbolic interaction that is a phone call and how our interactions on WhatsApp have been a part of the wider global phenomenon of transnationalism. The products of our everyday interactions have come to exemplify the greater experience of transnationality and its permeation into the daily experiences of transmigrants. The phone call becomes symbolic in the transnational context because of its transformative force and its impact on facilitating transnational relationships, interactions, practices, identities, global care networks, and ways of belonging.

This ethnography has explored the ways in which transnationalism has been conceptualised in existing scholarship: transnationalism has been understood to be the process, product, practice, identity construct, and embeddedness of a "here and there" dynamic (Duong 2015, 233) that exemplifies the wider social phenomenon of globalisation and profound interconnectivity. Transnationalism affects and permeates the lives of people who participate in cultures outside of their nation-state societies, regardless if they are migrants themselves or have a narrative of migration. Practising transnationalism in our increasingly digitised world can take place in both the offline and online spheres of interaction. These practices have huge consequences and wider sociocultural impacts on how transnationalism can be further engaged with and studied in the twenty-first century. Furthermore, transnationalism as an economic, political, and socio-cultural phenomenon has the potential of epic proportions to contribute to how we understand what constitutes society, migrant identities, home, belonging, and rich and meaningful human connections. It is a phenomenon that is experienced rapidly and globally, and it is increasingly becoming widely accessible to social actors all over the globe. Transnationalism is transforming the ways in which we understand, connect, and interact with one another while also changing the landscape of what it means to belong.

This research paper aimed to capture a meaningful everyday experience of the transnational in order to contribute to existing theories and research on transnationalism and to reframe how we have grown to understand the scope of transnationalism. This study confronts the dominant model of the nationstate framework, its limitations, and the need for critical adaptation. This research paper examined the outdatedness of the methodological nationalism framework and turned its focus toward more contemporary theoretical approaches like the new paradigm proposed by Levitt and Glick Schiller (2004) and Bourdieu's social field. By utilising this new paradigm as a contemporary transnational lens, the research has engaged with ideas of simultaneity, ways of being and ways of belonging, and the emergence of transnational and transmigrant identities. Furthermore, this research project has explored the creative possibilities of narratology as a creative methodology. By providing snapshot encounters into Grandma and I's everyday lives, this paper has illuminated the increasingly transnational nature of our everyday lives. Using creative and experimental methodologies such as narratology enhances our understanding of transnationalism in the contemporary context. New and creative methods of research on transnationalism need to be engaged with and applied to research on migration and transnationalism. Furthermore, applying the transnational lens moves beyond the framework of methodological nationalism, which has long dominated the discussion, but how have researchers adapted to these theoretical frameworks in our ethnographic inquiry? As researchers, we need to evolve our research methodologies, subjects, modes of analysis, and theories alongside the rapidly changing landscape of globalisation, its role in wider social processes, and its implications for 
anthropological studies. New methods that capture a more holistic and nuanced transnational dynamic are necessary. Ethnographic inquiry into evolving technologies, interactions, human connections, social relationships, and networks of care must evolve alongside our growing understanding of transnationalism and what it means to belong globally.

The core of this research has highlighted the transformative forces of transnationalism in all its forms, particularly in the emergence of transnational identities and transmigrants' efforts to navigate belonging within the transnational context. How do individuals who partake and hold allegiances to more than one nation-state or beyond mere nation-state boundaries recognise, acknowledge, and express their sense of belonging? How can we, as anthropologists, begin to study, understand, and write about this complex, interwoven, interconnectedness of the human experience? How will human connections as we understand them transform in the future? The entirety of this experience has provided a rich and meaningful way of engaging with transnationalism at an individual level. My study attempts to grasp and connect with the complex, interwoven individual interactions that exemplify the meaningfulness of wider global social phenomena in the transnational context. The implications of transnationalism are profound and paramount; it is transforming how we have grown to understand human interaction, connection, belonging, and care networks while simultaneously redrawing the boundaries of social life. 


\section{星期天 (Sunday)}

It's now been ten months since the first phone call in this research project took place. It's July now, and today I am sitting on the balcony of our high rise apartment in Singapore. It's been seven months since I've been home in my orange painted room in Perth. I'm home from Hong Kong for the summer, and the morning sun is exactly how I remember it to be. It is still casting warm dappled light on the tiles, and the breeze is the perfect temperature that soothes the stifling humidity, which is beginning to stir.

In my mind, I take a photograph of my grandparents as a way of remembering them, as a way of remembering them like this. Soon, I will be back in Hong Kong and they will be 2585 kilometres away, and it will be another three months before I see them again.

But today, Āmā (阿嫲) is only half a metre away from me and GōngGong (公公) is reading the morning newspaper. There is no longer a countdown app on my phone because I am seeing them right now. Āmā (阿 嫲) is smiling at me because she knows that I am writing about her and grandpa, about us, and telling the world a story of what it means to belong. Stories of being here and there, stories of home and how it is we love someone even if they are halfway across the world.

Perhaps, in telling and in writing these stories of us, I am trying to navigate where it is I belong in the world, where home is for me-only to realise that for a long time now, home is all over the world. 


\section{Acknowledgements}

This paper is dedicated to Āmā (阿嫲)and GōngGong (公公), without whom this paper would not be possible. Thank you for your love, openness, stories, and experiences. Special thanks to my professor Martin Forsey: your continuous support, mentoring, and encouragement in the classroom and through our transnational correspondence has been tremendous in shaping me into the researcher I am growing to be. Thank you to Martha Radice and the editorial team at JUE for making this possible.

\section{Endnotes}

${ }^{1}$ Translates to Grandmother.

${ }^{2}$ Translates to little cat, but the nickname sounds like Pui Pui, which does not exist as a Chinese or English word. I was nicknamed by my grandparents when I was born, after a kitten my mother had as a child.

${ }^{3}$ Translates to Grandfather (maternal).

${ }^{4}$ Then known as Nanyang Institute of Technology. 


\section{References}

Asher, Nina. 2008. "Listening to Hyphenated Americans: Hybrid Identities of Youth from Immigrant Families." Theory Into Practice 47 (1): 12-19.

Bal, Mieke. 1990. "The Point of Narratology." Poetics Today 11 (4): 727-753.

Baldassar, Loretta, Mihaela Nedelcu, Laura Merla, and Raelene Wilding. 2016. "ICT-based Co-presence in Transnational Families and Communities: Challenging the Premise of Face-to-face Proximity in Sustaining Relationships." Global Networks 16 (2): 133-144.

Baldassar, Loretta and Laura Merla. 2013. Transnational Families, Migration and the Circulation of Care Understanding Mobility and Absence in Family Life. Taylor and Francis: Florence.

Balogun, Oluwakemi M. 2011. "No Necessary Tradeoff: Context, Life Course, and Social Networks in the Identity Formation of Secondgeneration Nigerians in the USA." Ethnicities 11 (4): 436-66.

Bhabha, Homi K. 1994. The Location of Culture. Routledge: United Kingdom.

Blumer, Herbert. 1969. Symbolic Interactionism: Perspective and Method. Prentice Hall: Englewood Cliffs, New Jersey.

Bucher, Birgit. 2020. "WhatsApp, WeChat and Facebook Messenger Apps - Global Messenger Usage, Penetration and Statistics." MessengerPeople. Last modified February, 12th, 2020. https:// www.messengerpeople.com/global-messenger-usage-statistics/ \#: :text=With\%202\%20billion\%20active\%20users,over\%20800\% 20million\%20active\%20users.

Bullingham, Liam, and Ana C. Vasconcelos. 2013. "The Presentation of Self in the Online World': Goffman and the Study of Online Identities." Journal of Information Science 39 (1): 101-12.

Duany, Jorge. 2011. Blurred Borders: Transnational Migration between the Hispanic Caribbean and the United States. Chapel Hill, NC: University of North Carolina Press.

Duong, Lan P. 2015. "Transnationalism." In Keywords for Asian American Studies, edited by Cathy J. Schlund-Vials, Linda Trinh Võ and Kevin Scott Wong, 232-234. New York: NYU Press. 
Gajjala, Radhika. 2006. "Consuming/Producing/Inhabiting SouthAsian digital diasporas." New Media \& Society8 (2): 179-185.

Geertz, Clifford. 1975. The Interpretation of Cultures. New York: Basic Books.

Glick Schiller, Nina, Linda Basch, and Cristina Szanton Blanc. 1995. "From Immigrant to Transmigrant: Theorizing Transnational Migration." Anthropological Quarterly 68 (1): 48-63.

Harris, Anne. 2016. “The Way We Weren't: False Nostalgia and Imagined Love." Qualitative Inquiry22 (10): 779-784.

Hogan, Bernie. 2010. “The Presentation of Self in the Age of Social Media: Distinguishing Performances and Exhibitions Online." Bulletin of Science, Technology \& Society 30 (6): 377-86.

Levitt, Peggy, and Nina Glick Schiller. 2004. “Conceptualizing Simultaneity: A Transnational Social Field Perspective on Society." The International Migration Review38 (3): 1002-1039.

Madianou, Mirca, and Daniel Miller. 2012. "Polymedia: Towards a new theory of digital media in interpersonal communication." International Journal of Cultural Studies 16 (2): 169-187.

McGranahan, Carole. 2015. "Anthropology as Theoretical Storytelling." https://savageminds.org/2015/10/19/anthropologyas-theoretical-storytelling/

Merla, Laura, and Loretta Baldassar. 2011. "Transnational caregiving between Australia, Italy and El Salvador: the impact of institutions on the capability to care at a distance." In Gender and Well-being: The Role of Institutions, edited by Elisabetta Addis, Paloma de Villota, Florence Degavre and John Eriksen, 147-162. Farnham: Ashgate.

Merla, Laura. 2015. "Salvadoran migrants in Australia: an analysis of transnational families' capability to care across borders." International Migration 53 (6): 153-165.

Miller, Daniel. 2009. Anthropology and the Individual: A Material Culture Perspective. Oxford: Bloomsbury Publishing.

Nedelcu, Mihaela. 2013. “(Re)thinking transnationalism and integration in the digital era: a shift towards cosmopolitanism in the study of international migrations." In Critical Mobilities, edited by Ola Söderström, Shalini Randeria, Didier Ruedin, Gianni D'Amato and Francesco Panese, 153-175. Abingdon: Routledge. 
Raab, Rebecca. 2018. "A Statistic's Five Years: A Story of Teacher Attrition." Qualitative Inquiry 24 (8): 583-591.

Walrath, Dana. 2011. "Alzheimer's through the Looking Glass: The Anthropology of Everyday Life." Anthropology Now3 (3): 64-97.

Wilding, Raelene, and Loretta Baldassar. 2018. “Ageing, migration and new media: The significance of transnational care." Journal of Sociology 54 (2): 226-235.

Wyatt, Jonathan. 2012. "Fathers, Sons, Loss, and the Search for the Question." Qualitative Inquiry18 (2): 162-167.

\section{(c) $(i)(9)$}

This work is licensed under a Creative Commons Attribution-NonCommercialNoDerivatives

4.0 International License. 